Some discrepancies exist in the calculations of various authors as regards the mortality of this operation. Phillips states that out of 171 cases he has collected, 57 died. Lisfranc states that he has collected the reports of 180 cases where the Hunterian operation has been performed, and gives the deaths at $\mathbf{4 0}$ only.

The above table is drawn out after carefully examining all the medical periodicals for a long series of years, and the author believes it may be relied on as being the closest possible approximation to the actual truth.

Table shewing the Mortality attending the operation for Lithotomy.

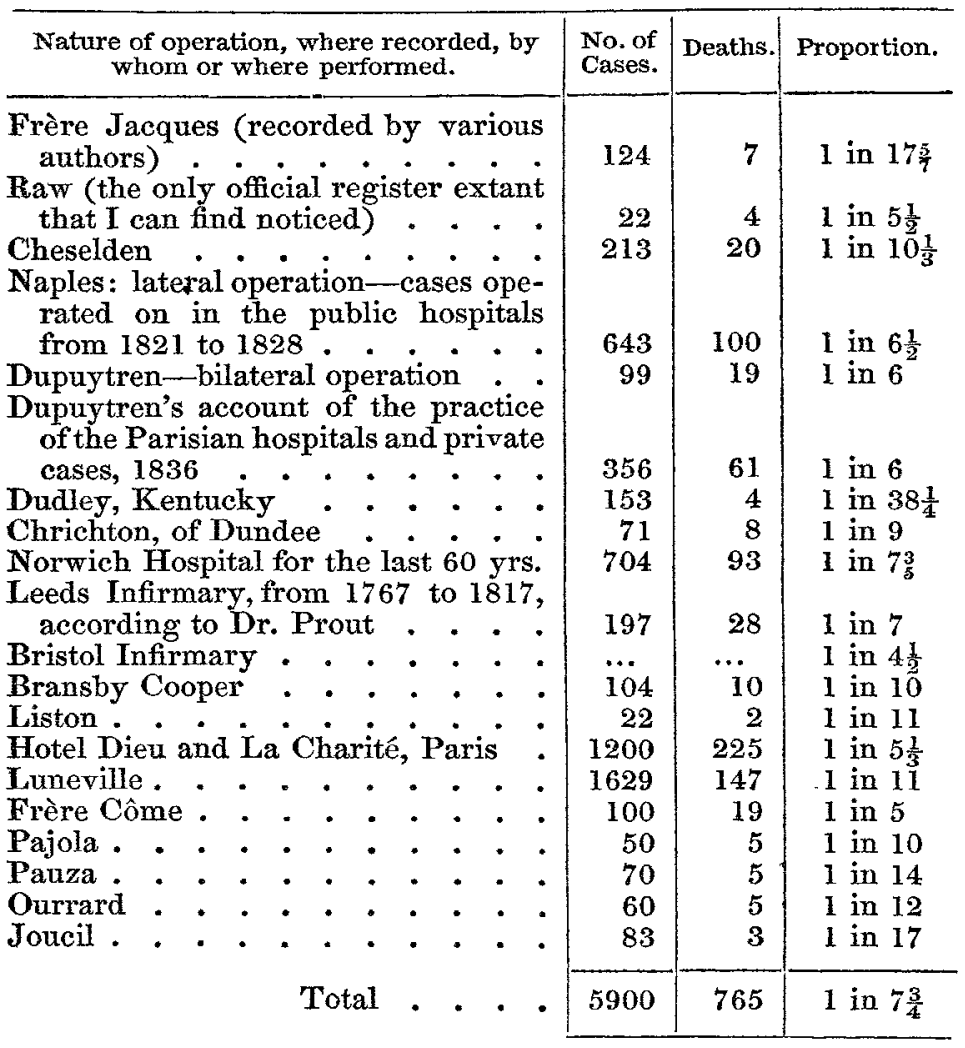

Table shewing the Mortality attending the operation for Hernia.

\begin{tabular}{|c|c|c|c|}
\hline Where or by whom recorded \&c. & $\begin{array}{l}\text { No. of } \\
\text { Cases. }\end{array}$ & $\begin{array}{l}\text { No. of } \\
\text { Deaths. }\end{array}$ & Proportion. \\
\hline 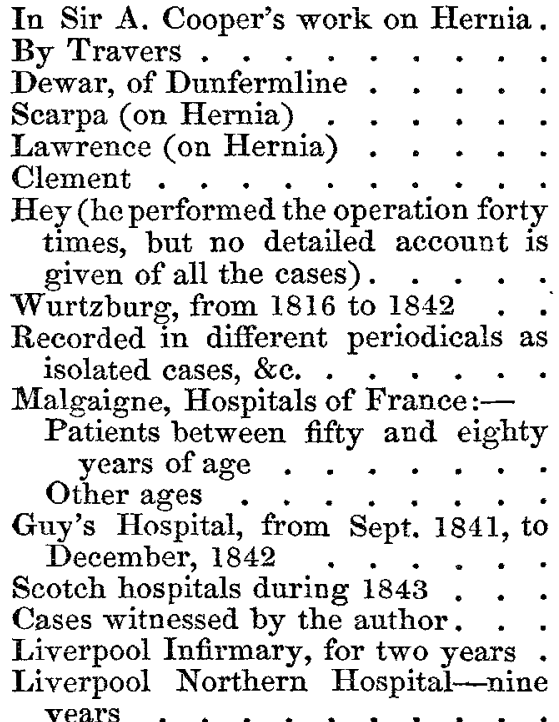 & $\begin{array}{r}77 \\
14 \\
17 \\
16 \\
22 \\
8\end{array}$ & $\begin{array}{r}36 \\
8 \\
4 \\
5 \\
7 \\
3\end{array}$ & $\begin{array}{l}1 \text { in } 1 \frac{1}{4} \\
1 \text { in } 2 \\
1 \text { in } 2 \\
1 \text { in } 3 \frac{2}{3} \\
1 \text { in } 2 \\
1 \text { in } 4 \\
1 \text { in } 2\end{array}$ \\
\hline Total . . . & 545 & 260 & 1 in 2 \\
\hline
\end{tabular}

Table shewing the Mortality attending upon the operation of Gastrotomy and the Casarian Section.

\begin{tabular}{|c|c|c|c|}
\hline $\begin{array}{l}\text { Where or by whom recorded-Nature } \\
\text { of operation \&c. }\end{array}$ & $\begin{array}{l}\text { No, of } \\
\text { Cases. }\end{array}$ & Deaths. & Proportion. \\
\hline 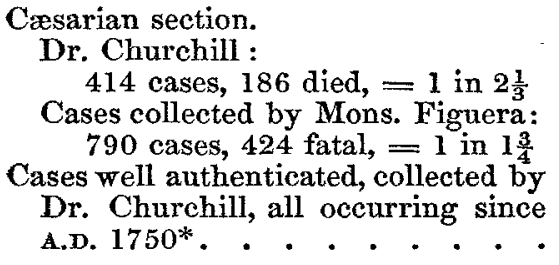 & 321 & 172 & \\
\hline $\begin{array}{l}\text { Removal of Dropsical Ovarium, where } \\
\text { operation was completed. } \\
\text { Operation for extirpation, where } \\
\text { either no tumour existed, or where } \\
\text { insurmountable obstacles prevented } \\
\text { the removal of the diseased mass. } \dagger\end{array}$ & 33 & 11 & $\begin{array}{l}1 \text { in } 3 \\
1 \text { in } 3\end{array}$ \\
\hline Total . . . & 363 & 186 & $\left\{\begin{array}{c}1 \text { in } \\
\text { about } 2\end{array}\right.$ \\
\hline
\end{tabular}

1, Rodney-street, Liverpool, May 15, 1844.

\section{SOME FURTHER PRACTICAL REMARKS ON THE TREATMENT OF OVARIAN DROPSY.}

By IsaAc B. Brown, Consulting Surgeon-Accoucheur to the Paddington Lying-in Charity, \&c. \&c.

I AM most anxious to have my plan of treatment fairly before my professional brethren, convinced that good will ensue if all the plan is systematically carried out. I am most particular on one point-viz, the ages of my patients who have been cured, as much has been said on that head tending to militate very materially against my cases as being true ovarian. When Mr. B. Philips read his excellent paper on the recorded cases of the operation for removal, before the Royal Medical and Chirurgical Society, I was allowed to make some observations upon my plan of treatment; after which Dr. F. Bird spoke to the following effect:- " It required very little to prove that the plan recommended by Mr. Brown was inefficient; the age of the individuals was against the supposition that the dropsy under which they suffered was ovarian."

Now, a doubt as to my cases being ovarian coming from Dr. F. Bird, who has successfully operated in several cases, is calculated to prejudice very seriously the minds of my professional brethren; I therefore purpose shewing from facts-for from facts alone I have hitherto drawn all my deductions, - - that his objection is not valid. First, let me recapitulate the ages of the cases recorded: they are respectively $17,20,19,17,45$. Now, supposing the theory that ovarian disease cannot take place before the age of puberty, to be correct, (which I have always dissented from, as stated in my second paper, published in THE LANCET, ) still their ages were not so young as to prevent the full development of the sexual organ, and they had all menstruated. Again: have not several writers for the past century mentioned cases of ovarian disease as early as 13 and 14; and have not surgeons lately operated for the removal of the cyst on patients as young as 20? Has not Dr. F. Bird himself operated lately on a young lady aged 21 ? - and does not her past history prove that the disease commenced as early as 18? But further: I have lately had under my care a young lady, whose case I pronounced to be ovarian on my first visit, and whose age was only 15 , and she had never menstruated, but her past history shewed that the disease had been coming on for at least a year previously. I have since tapped her in the presence of my esteemed friend Mr. Lane,-whose opinion I suppose Dr. F. Bird and others will allow is likely to be as good as, if not better than that of any other surgeon,- who has seen much of ovarian disease and its peculiar fluid, and agrees with me, and others present, that the disease is decidedly ovarian. I have a portion of the fluid (in all twenty pints) in a bottle, which I shall be happy to shew to Dr. Bird, or any one else who doubts its character; they will find that it is of a coffee-ground colour, thick, ropy, and highly albuminous-all acknowledged

* Ont of twenty-eight persons wro had the operation performed on them more than once, only thrce died-i.e., the ece were seventy-three operations on twenty-eight persons, and only three deaths.-(Fro $n$ Dr. Churchill's Midwifery, \&c.) 
signs of one form of ovarian disease. I hope this case clearly establishes the fact that the disease does occur in young females, (even before the age of puberty;) and if it do establish such fact, I think no one will be likely to doubt the character of my recorded cases, on account of their ages.

I have been repeatedly asked what class of ovarian disease I consider most likely to benefit by my plan of treatment? I would wish to refer them to the excellent and truly practical remarks made by Dr. Moore at the same meeting of the Royal Medical and Chirurgical Society as $I$ have just alluded to. He remarks: "There were three forms of disease most commonly observed. In the first form, the ovary itself became diseased and degenerated, a sac formed, and went on enlarging more or less; the fluid contained in the sac was thin and watery. This form of the disease might probably exist for years. In the second form of the affection, each Graafian vesicle was affected, and became enlarged, forming, in appearance, a tumour similar to the first variety, but it contained a thick, yellow, tenacious fluid, this fluid being contained in different cells : in this variety paracentesis was of no benefit. 'The third class of the affection was altogether different from the two others; it appeared to have its origin in irritation or inflammation of parts contiguous to the ovary, in some instances simulating peritoneal inflammation; its situation appeared to be between the ovary and peritoneum, and it contained a thick, ropy fluid."

Now it is the first form of disease I consider favourable for treatment, and I willingly confess that where, after every trial, the disease should prove one of the second or third class, then the median operation is to be recommended as a legitimate operation. But it is asked-How are you to know what is the precise character of the disease? I answer, There is no certain means except tapping the patient, to ascertain the character of the fluid, yet there are certain general signs which may give you a tolerable good idea of the nature of the disease.

It will be generally found, that in the first form decrease of size takes place much more certainly than in either of the other forms; under rational medical treatment there will generally be less constitutional disturbance; the past history will be more marked; but without being certain of the character, a fair trial should be given, and I cannot see any harm that can arise when directed by a competent medical man. of course, in the hands of a careless practitioner, or in the hands of a would-be medicus; the mercurial treatment might be serious, and even dangerous.

Again: objection has been frequently made to my cases bein genuine, on account of the fluid in some of them being thin and watery; it has been urged that such is not the proper character of the fluid. I can only refer them to almost every writer on ovarian disease, to prove that in the simple encysted, the fluid is almost invariably of a thin, light-brown, and watery character, or, in the words of Dr. F. Bird, when describing his last case, "the fluid was of a light-amber colour, containing but little albumen." $I$ could easily multiply instances of well-recorded cases to prove this point, but I am not desirous of extending these remarks beyond their present limits. I shall always, however, be ready to defend my assertion, if any one can be found to doubt its accuracy.

Connaught Terrace, Hyde Park.

\section{ON AN IMPROVED MODE OF MANAGING BLISTERS.}

\section{By John Kex Robertson, M.D., Glasgow.}

IN a monograph on "Special Diseases," published by me in 1841, I described a mode of managing cantharides as a blister, the general purport of which I shall repeat here, that it may be extensively read and tried through the wide circulation of THE LANCET.

I beg leave to say, that what follows is the result of my observation, extending over nearly seventeen years, and that if the practice be followed anywhere, or by any one, it has never been made public but by myself, so far as is known to me.

I shall be extremely glad that it be given a fair trial generally, by gentlemen in the profession, and that the results be sent to The Lancet for publication.

The improvements $I$ beg to suggest are the following:-The common empl. canth. of the pharmacopcia is to be used.

I. It is generally spread on leather.

It should never be spread on leather, but on thin paper, (partially sized, or printing paper,) or upon soft linen. Leather, by the heat of many parts of the body, becomes dry, partially crisp and with difficulty adheres to the skin, producing, even if the blister were otherwise good, an impossibility in many instances of acting well and generally over the whole part intended to be blistered, from not being over the whole extent of the blister in contact with the surface of the hody. The linen or paper has no such objection, and clings easily and to anywhere. I invariably use paper, and straps to secure it, above these a small pad, and then a bandage.

II. It is generally spread very thick.

It should be spread very thin-a mere covering of the paper or linen is all that is requisite. This thickness partakes of the objection already mentioned with reference to leather; and as no more than the mere surface of the blister can act on the skin, to make a blister thick is, in addition to rendering it in many places difficult of application or adhesion, sillily throwing away, or wasting, a rather expensive substance.

III. It is a very common practice to cover the surface with powdered cantharides. This should never be done, but instead, a few drops of olive or sweet oil put on the surface of the spread blister, the oil, by means of the finger, being rubbed into its surface and allowed to remain.

There are several objections to the practice of putting powdered cantharides on the surface of blisters. In the first place, a good one does not need it. In the second, a bad one wont be made good by its being there, as dry cantharides act very triflingly, or not at all, on the skin; and again, if the blister act it is troublesome to remove from the surface, thereby increasing the chances of strangury by absorption, or forcing us to tear off the cuticle to obtain its removal.

The active property of Spanish fly is soluble in fixed oil. This, it may be said, is perfectly well known; possibly, it is well known; but while the simple empl. canth. of the shops will act occasionally tolerably well in summer, in winter it is far otherwise; the vehicle is then almost solid, and my proposal is a means of obtaining the activity of the Spanish fly at all seasons, and independently of ordinary counteracting circumstances. Its activity by this means is not only rendered certain, but more intense, much less time being necessary to blister than usual, six to eight hours being quite enough, and even less will do where time is of importance.

The skin requires no preparation whatever-strangury never follows with me. They are dressed afterwards in the ordinary way, with cotton. If the oil has been rubbed into the blister a few hours before being used, so much the better.

Circumstances which I need not detail here have forced me to have a blister on my own person this week. I used one as advised here. It rose beyond anything gentlemen using the ordinary blister in the ordinary way are accustomed to see, and gave me little or no annoyance.

Patients soon begin to discover the superiority of means in the hands of different practitioners. Those who have used these blisters prefer them to every other. It is only a few weeks ago that I received written messages from different parties, both of them ladies residing in neighbouring counties, containing many apologies for making such a request, but begging a blister of the kind used by me to be sent per post, giving as a reason, that they had been my patients some two or three years before, and had then used them; were now ordered blisters by their present medical attendants, \&c.

In some instances, blisters produce a vast deal of irritation. I have met with persons who, from this cause, were perfectly alarmed at the bare idea of a blister. These are cases in which the form of blister recommended here will be found to answer admirably, and will repay those who choose to give it a trial. One lady I recollect, from Brighton, told me she never could be blistered, that it projuced the greatest distress, that her skin could not tolerate it, \&c. She lived to learn that she could be blistered like her neighbours.

None of the blistering tissues recommended and puffed by those interested in selling them are, in my estimation, to be compared to the means narrated.

Every man can make this blister for himself, of the commonest materials, at a very trifling expense, and if this be any recommendation, they will act three, four, or six times, if uninjured, and the oil gently renewed on the surface.

West Hill-street, Glasgow, June 18, 1844.

\section{SULPHATE OF IRON COMBINED WITH AN ALKA-} LINE CARBONATE, AN ANTIDOTE FOR PRUSSIC ACID.

\section{By J. \& J. H. Sмiтr, Edinburgh.}

IN a communication, dated 3rd July last, which THE LanceT did us the honour of inserting, we proved, we believe, that common sulphate of iron, used by itself, was not possessed of the slightest antidotal action against the poisonous effects of prussic acid. We at the same time intimated our being engaged in some 